\title{
LA BIBLOTECA DIGITAL OVIDIANA: UN PROYECTO PATRIMONIAL DE VOCACIÓN ICONOGRÁFICA SOBRE EL «OVIDIO ILUSTRADO» ${ }^{1}$
}

\author{
FÁTIMA DíEz Platas \\ Universidad de Santiago de Compostela
}

\section{RESUMEN}

Esta contribución expone la descripción, origen y desarrollo del proyecto de investigación financiado Biblioteca Digital Ovidiana, que se encuentra en la quinta fase de implementación. El proyecto, cuya investigación se desarrolla dentro de las bibliotecas con fondo antiguo que poseen ejemplares de las ediciones ilustradas de la obra del poeta romano Publio Ovidio Nasón, ha producido un sitio web especializado en la obra ovidiana a través del que se difunde la investigación y se ofrece una herramienta digital para el estudio del libro, de la tradición de la ilustración de las obras ovidianas y de la iconografía del mito entre los siglos XV y XIX.

Palabras clave: Biblio-iconografía, ediciones ilustradas, Metamorfosis, grabados, Web semántica.

1 Este artículo forma parte de los resultados del proyecto de investigación Biblioteca Digital Ovidiana: ediciones ilustradas de Ovidio, siglos XV-XIX (V): Las bibliotecas de las CC.AA. de Andalucía, Extremadura, Canarias, Ceuta y Melilla (HAR2017-86876-P), financiado por el Ministerio de Economía y Competitividad. Quiero agradecer a José Julio García Arranz la oportunidad de presentar el proyecto en este interesante foro. 


\section{ABSTRACT}

This contribution sets out the description, origin and development of the research project Ovidian Digital Library (Biblioteca Digital Ovidiana), which is in its fifth phase of implementation. The project, whose research is carried out within the libraries with ancient collections that have copies of the illustrated editions of the works of the Roman poet Publius Ovidius Naso, has produced a specialized website on the Ovidian illustration to spread the completed research and to offer at the same time a powerful digital tool for the study of the book, the tradition of the illustration of Ovidian works, and the iconography of myth between 15 th and 19th centuries.

Keywords: Biblio-iconography, illustrated editions, Metamorphoses, engravings, Semantic Web.

\section{INTRODUCCIÓN AL PROYECTO BIBLIOTECA DIGITAL OVIDIANA}

El proyecto Biblioteca Digital Ovidiana: ediciones ilustradas de las obras de Ovidio en las bibliotecas españolas (siglos $X V$-XIX) es un proyecto de investigación competitivo financiado que está planteado, en primera instancia, como un proyecto de corte patrimonial que tiene dos objetivos básicos. El primero de ellos es la localización y el estudio de todos los ejemplares de las ediciones ilustradas de las obras de Ovidio impresas entre los siglos XV y XIX que se conservan en las bibliotecas españolas; el segundo, difundir la información bibliográfica e iconográfica que procede del estudio de los ejemplares localizados y estudiados a través de la creación de una plataforma digital.

Como iniciativa global, el proyecto se concibió desde el principio como un proceso en desarrollo que se desenvuelve en fases sucesivas. Este proceso comienza en 2008 con la primera, Biblioteca Digital Ovidiana: ediciones ilustradas de Ovidio, siglos XV-XIX (I): las bibliotecas de Galicia y Cataluña (HUM200760265/ARTE), que se extendió hasta el año 2010. En esta fase se inicia el rastreo y el conocimiento de las ediciones ilustradas de las obras ovidianas, en primer lugar, en las bibliotecas de Galicia y en las bibliotecas de Cataluña, las comunidades autónomas en las que se desarrollaba el trabajo de la investigadora principal, Fátima Díez Platas, de la Universidad de Santiago de Compostela, y uno de los miembros del equipo de investigación, Manuel Antonio Castiñeiras González, de la Universidad Autónoma de Barcelona. Las consultas y el trabajo desarrollado en las bibliotecas de ambas comunidades revelaron que el conjunto de la obra ilustrada conservada en las instituciones visitadas era mucho más abundante 
de lo que se había determinado en las primeras búsquedas en los catálogos y repertorios a disposición. Esta circunstancia supuso la modificación de la planificación de trabajo y motivó la petición de un nuevo proyecto dedicado de manera específica a los ejemplares de las bibliotecas de Cataluña para poder llevar a cabo la localización y consulta de todos los ejemplares de todas las bibliotecas visitadas. Esta segunda fase, Biblioteca Digital Ovidiana: ediciones ilustradas de Ovidio, siglos XV-XIX (II): las bibliotecas de Cataluña (HAR2010-20015), se extendió durante los años 2011 y $2012^{2}$. Entre 2012 y 2014 se llevó a cabo la fase III, Biblioteca Digital Ovidiana: ediciones ilustradas de Ovidio, siglos XV-XIX (III): las bibliotecas de Castilla y León (HAR2011-25853); entre 2015 y 2017, la cuarta fase Biblioteca Digital Ovidiana: ediciones ilustradas de Ovidio, siglos $X V$-XIX (IV): las bibliotecas de Madrid (HAR2014-55617-P), y en 2018 comenzó la quinta fase, Biblioteca Digital Ovidiana: las ediciones ilustradas de Ovidio, siglos XV-XIX (V): las bibliotecas de las CC.AA. de Andalucía, Extremadura, Canarias, Ceuta y Melilla (HAR2017-86876-P), en esta ocasión un proyecto de cuatro años, que se extenderá hasta 2021.

De manera general, el proyecto aspira a contemplar todos los ejemplares de las ediciones ilustradas de entre los siglos XV y XIX que se encuentran en las bibliotecas españolas. Y este intento de recopilación exhaustiva de ejemplares, y no sencillamente la búsqueda y estudio del conjunto limitado de las ediciones ilustradas producidas en ese rango de tiempo, tiene sentido desde dos puntos de vista. Por una parte, desde el punto de vista de la recuperación del patrimonio bibliográfico español, se contribuye a la localización de la obra ilustrada con objeto de rescatar piezas desconocidas, identificar ejemplares mutilados o dañados que han perdido sus características definitorias, como la portada, colofón o la información clave para la identificación de la edición. Por otra parte, este deseo de revisar todos y cada uno de los ejemplares se imbrica, además, en la línea renovada de la Historia Material del Libro, que hace tomar conciencia sobre la importancia de la vida de los ejemplares que habla de sus poseedores, que proporciona datos sobre la lectura de la literatura clásica, y sobre el interés en las bibliotecas españolas y los lectores por un autor como Ovidio, contemplado a través de la presencia de libros especiales, ornados, de cuidada edición o especialmente valiosos por la adición de imágenes, hecho que los convierte en verdaderas obras de arte, con frecuencia alteradas o enriquecidas por decisión del poseedor.

2 Originariamente solicitado como un proyecto de un año para terminar con las ediciones de Cataluña y la puesta en marcha del sitio web, que hubo que prorrogar seis meses y terminó por tanto en 2012, solapándose con la siguiente fase. 
No obstante, además de la labor de recuperación, difusión, estudio y valoración de una parte del patrimonio bibliográfico español, el proyecto tiene el objetivo más amplio y ambicioso de acometer un estudio sistemático de la ilustración de la obra ovidiana y, en última instancia, de intentar indagar en los procedimientos figurativos y los mecanismos de la creación de imágenes para ilustrar los contenidos poéticos. Este objetivo secundario deriva de la conciencia del conocimiento experto que se obtiene a través del estudio de los ejemplares ilustrados. Los riquísimos contenidos visuales que se encuentran, sobre todo en las imágenes que adornan las numerosas ediciones acompañadas de estampas del poema de las Metamorfosis, han estimulado esta investigación que está en curso como una línea abierta en relación con el trabajo bibliográfico. Por añadidura, la posibilidad de conocer y estudiar la mayoría de las versiones ilustradas de la producción ovidiana, cuyos ejemplares se encuentran en las bibliotecas españolas, ofrece la posibilidad de abordar un tipo más de estudio que ensaya una «mirada doble» al libro, contemplando las cuestiones de la relación texto-imagen.

De este modo, el proyecto Biblioteca Digital Ovidiana (a partir de ahora $B D O$ ) se presenta como un entorno de investigación multidimensional -patrimonial, bibliográfico, iconográfico, literario y digital- que cuenta con un equipo multidisciplinar para su desarrollo, aunque parte de la iniciativa individual de la investigadora principal, Fátima Díez Platas, profesora del departamento de Historia del Arte de la Universidad de Santiago de Compostela. La labor de Díez Platas se enmarca en el estudio de la iconografía del mito de manera transversal, como respuesta a su variopinta formación como historiadora del arte, historiadora de la Antigüedad y filóloga clásica. El equipo de investigación, que ha ido variando en las diferentes fases para incluir expertos radicados en las comunidades objeto de estudio en cada uno de los momentos ${ }^{3}$, incluye, sin embargo, de manera constante desde la segunda fase del proyecto a dos expertas en informática y programación ${ }^{4}$ que se han ocupado de transformar el trabajo con los ejemplares en las bibliotecas y la información analógica obtenida en los materiales digitales que alberga el sitio web de la $B D O^{5}$, desarrollado como plataforma de difusión patrimonial de la obra ilustrada de Ovidio en las bibliotecas españolas y como una herramienta de estudio y conocimiento

3 Dr. Manuel Castiñeiras González, Historia del Arte, Universidad Autónoma de Barcelona (2008-2012); Dr. Joaquín García Nistal, Historia del Arte, Universidad de León (2012-2014); Dr. José Moráis Morán, Historia del Arte, Universidad de León (2012-2014); Dra. María Gloria González Galván, Filología Clásica, Universidad de La Laguna (2018-actualidad).

4 Dra. María Luisa Díez Platas, Matemáticas-Ciencias de la Computación, e Informática, Universidad Internacional de La Rioja (UNIR), y Dra. Paloma Centenera Centenera, Informática, Universidad Católica de Ávila.

5 http://www.ovidiuspictus.es/bdo.php [Consulta: 20/11/20] 
de la ilustración mitológica y las imágenes ovidianas. Por su parte, el equipo de trabajo, que también ha ido variando con las distintas fases, está constituido por un grupo de doctorandas de Historia del Arte y Estudios Clásicos que trabajan sobre diversos aspectos de la edición ilustrada de las obras de Ovidio y las imágenes que se han generado a partir de ellas ${ }^{6}$.

\section{ORIGEN Y ANTECEDENTES DE LA $B D O$}

El origen de la $B D O$ se encuentra en la iniciativa personal de la investigadora principal de comenzar a estudiar la iconografía de los grabados de las ediciones ilustradas de las Metamorfosis de Ovidio en los últimos años de la década de los 90, que partió de la toma de contacto con los ejemplares de una serie de ediciones ilustradas del poema del siglo XVI que posee la Biblioteca Universitaria de Santiago de Compostela ${ }^{7}$. El trabajo con los grabados de las distintas ediciones se convirtió pronto en materia académica para realizar ejercicios de lectura de la imagen con los alumnos de Historia del Arte en diversas asignaturas de licenciatura y doctorado. Una parte de las propuestas de lectura iconográfica de las ilustraciones de veinticinco episodios distintos narrados en el poema de las Metamorfosis se convirtieron en un libro de la investigadora principal-Imágenes para un texto. Guía Iconográfica de las 'Metamorfosis' de Ovidio $^{8}$ - en el que se explora de manera especial la relación de los textos de las historias del poema con las imágenes que se derivan de ellas.

De este interés por la imagen ovidiana surgió la iniciativa del primer proyecto de investigación competitivo concedido a la investigadora principal, «Estudio iconográfico del Ovidio figurado español: las imágenes de las Metamorfosis desde el medievo al siglo XVII», financiado por el Ministerio de Ciencia y Tecnología (BHA 2003-02187), que se ocupó de estudiar la iconografía completa de las ediciones ilustradas españolas de las Metamorfosis acompañadas de imágenes. Los resultados del proyecto se convirtieron en 2006 en un sitio

6 Patricia Meilán Jácome (2008-actualidad); Estíbaliz García Gómez (2008-2014); Brianda Otero Moreira (2015-actualidad); Nerea Senra Alonso (2016-actualidad); Nair Castiñeiras López (2016septiembre 2019); Marta Cerviño Solana (2019-actualidad).

7 Fruto de este primer acercamiento es el artículo realizado con el profesor Juan Manuel Monterroso Montero, quien sugirió a la investigadora principal el trabajo en este campo inexplorado de la iconografia: DÍEZ PLATAS, F. y MONTERROSO MONTERO, J. M., «Mitología para poderosos: las Metamorfosis de Ovidio. Tres ediciones ilustradas del siglo XVI en la Biblioteca Xeral de Santiago», en VIGO, A. (ed.), Cultura, poder y mecenazgo, Semata 10, Santiago de Compostela, 1998, pp. 451-472. Aprovechamos estas páginas para volver a agradecerle una sugerencia que ha fructificado de manera esplendorosa.

8 Santiago de Compostela, Tórculo Ed., 2000. 
$w e b^{9}$ que contenía los resultados del trabajo sobre el Ovidio figurado español, con estudios introductorios sobre la ilustración de las Metamorfosis y las ediciones españolas del poema, además del estudio iconográfico individualizado de cada uno de los grabados de las ediciones y su relación con el texto de cada una de las historias representadas. Este proyecto, que supuso la toma de contacto con la ilustración del poema ovidiano a través de dos ediciones españolas ilustradas producidas en el siglo $\mathrm{XVI}^{10}$, constituyó la base teórico-práctica del proyecto vigente Biblioteca Digital Ovidiana.

Desde el punto de vista de la idea de transformar el estudio de la ilustración de Ovidio en las ediciones en una biblioteca digital de ejemplares de un fondo patrimonial concreto, como es el del conjunto de España, cuyas motivaciones ya hemos expuesto, surgió de la necesidad de contar con un planteamiento práctico para construir un corpus de estudio concreto. La decisión, como hemos explicado al inicio, ha llevado aparejada la apertura de una línea de investigación, de vocación claramente iconográfica en el inicio, hacia otros entornos, como el propio libro y la biblioteca, que en realidad constituyen el contexto de la imagen que se pretende estudiar. Por otra parte, la idea de convertir todo ello en un recurso digital surgió de la mirada a los signos de los tiempos, pero también de la manera en que se había abordado el estudio del libro ilustrado y de la propia ilustración de Ovidio hasta el momento en el que se comienza a conformar el enfoque de la $B D O$, cuyos antecedentes nos gustaría glosar brevemente a continuación.

Desde el punto de vista de la Historia del Arte, la obra de Ovidio, que goza de una importancia capital como fuente de motivos mitológicos para los artistas, que utilizaron profusamente las ediciones ilustradas de las Metamorfosis que se multiplicaron a partir del siglo XV, no había merecido apenas atención en calidad de «Ovidio ilustrado». El acercamiento a la obra del poeta desde este ángulo no solo era escaso, sino que además no estaba actualizado y se había

9 El sitio web, realizado en Flash, ha estado alojado en el repositorio de la Universidad de Santiago de Compostela hasta este año, en que ha tenido que ser desactivado. En este momento está en proceso de migración al sitio web Ovidius Pictus, portal en el que se encuentra la Biblioteca Digital Ovidiana.

10 Los resultados del trabajo con estas ediciones se materializaron una serie de publicaciones: DÍEZ PLATAS, F. «Tres maneras de ilustrar a Ovidio: una aproximación al estudio iconográfico de las Metamorfosis figuradas del XVI», en FOLGAR Mª C, GOY, A. y LÓPEZ, J. M. (eds.), Memoria Artis I, Santiago de Compostela, Xunta de Galicia, 2003, pp. 247-267; DÍEZ PLATAS, F., «El Minotauro: ¿una imagen 'al pie de la letra'?», Quintana, 4, 2005, pp. 141-152; DÍEZ PLATAS, F., «El viaje de Orfeo, de la Antigüedad a la tradición clásica», Jornadas Insulae. La multiculturalidad en la Antigüedad clásica, Tenerife, 2007; DÍEZ PLATAS, F., GARCÍA GÓMEZ, E., PAZ FERNÁNDEZ, M. y LÓPEZ GÓMEZ, C., «Mitos de libro: la ilustración de las Metamorfosis de Ovidio en las ediciones españolas del siglo XVI», en GARCÍA MAHÍQUES, R. y ZURIAGA SENENT, V. F. (eds.), Imagen y Cultura. La Interpretación de las Imágenes como Historia Cultural I, Biblioteca Valenciana, Valencia, 2008, pp. 549-562. 
limitado algunos estudios aislados sobre ediciones concretas o algunos episodios, sin que se hubiera abordado en modo alguno un estudio de conjunto de las tradiciones figuradas y del panorama de las ediciones. De manera concreta, el único trabajo general sobre la ilustración de la obra de Ovidio era el pequeño opúsculo de G. Duplessis, Essai bibliographique sur les différentes éditions des oeuvres d'Ovide ornées de planches publiées aux XVe et XVIe siècles (París, 1889), no más que un catálogo detallado de todas las ediciones con grabados que se producen entre los siglos XV y XVI: una mirada general en la que faltan muchas ediciones que no estuvieron al alcance del estudioso. El estudio de las ediciones ilustradas del poema de las Metamorfosis, en cambio, estaba más desarrollado, aunque una panorámica general casi completa solo se encuentra todavía en la obra fundamental de M. D. Henkel, «Illustrierte Ausgaben von Ovids Metamorphosen im XV., XVI. und XVII. Jahrhundert» ${ }^{11}$, que consiste en un ensayo exhaustivo sobre las ediciones con grabados de los siglos $\mathrm{XV}$, XVI y XVII, con una extensión de la influencia en los siglos XVIII y XIX, cuya aportación fundamental es ofrecer un panorama ordenado de la producción de ediciones ilustradas del poema. Pero, a pesar de tratar la génesis de la ilustración de las ediciones en Europa y analizar y presentar las características de las diferentes ediciones, el trabajo de los distintos grabadores, las copias que se subsiguen y la vida, en suma, de los juegos de grabados producidos para distintas versiones del poema, evidentemente no agota -no es un verdadero volumen, sino más bien un extensísimo artículo de noventa y una páginas más cuarenta y cinco páginas de ilustraciones- el estudio y la descripción de todos y cada uno de los grabados de los distintos modelos y temas ${ }^{12}$.

Desde los años 80 del siglo pasado, se produjeron algunos estudios concretos, en su mayoría sobre las ediciones del XVI, que, aunque contemplan y estudian el fenómeno de la ilustración, no proceden generalmente del entorno de la historia del arte y prestan relativa atención a los procesos iconográficos. Entre ellos hay que citar los trabajos de B. Guthmüller ${ }^{13}$, las tesis doctorales y los trabajos académicos que revisan ediciones específicas y prestan atención a

11 Vorträge der Bibliothek Warburg (1926-1927), 1930, pp. 53-144.

12 El propio Henkel es el autor de uno de los primeros estudios específicos sobre la que se considera la primera edición impresa de las Metamorfosis con ilustraciones, que ve la luz en Brujas en 1484: HENKEL, M. D., De Houtsneden van Mansion's Ovide moralisé, Bruges 1484, Amsterdam, 1922.

13 «Immagine e testo nelle Trasformationi di Ludovico Dolce», Mito, poesia, arte. Saggi sulla tradizione ovidiana nel Rinascimento, Roma, Bulzoni Editore, 1997, pp. 291-307, y «Picta poesis Ovidiana», en HEITMANN, K. y SCHROEDER, E. (eds.), Renatae Litterae: Studien zum Nachleben der Antike und zur europäischen Renaissance: August Buck zum 60. Geburtstag, Frankfurt. 1973 (versión italiana en Mito, poesia, arte: saggi sulla tradizione ovidiana nel Rinascimento, Roma, 1997, pp. 213-236). 
los juegos de grabados ${ }^{14}, \mathrm{y}$, sobre todo, los numerosos trabajos de Gerlinde Huber-Rebenich ${ }^{15}$. Esta investigadora y su equipo ya han publicado dos volúmenes ${ }^{16}$ que se enmarcan en el proyecto «Ovids Metamorphosen in der textbegleitenden Druckgraphik» sobre la ilustración de las Metamorfosis que, bajo la dirección de H. Walter y la propia Huber-Rebenich, aspira a producir un estudio de todos los tipos de ilustración y de todos los grabados que se encuentran en las ediciones del poema desde el siglo XV hasta el XIX. Concebido como una verdadera actualización y ampliación de la obra de M. D. Henkel, pretende ir más allá en el estudio detallado de los juegos de grabados y los motivos iconográficos, atendiendo a la naturaleza de las ediciones. De modo que este es, en parte, el modelo y a la vez el complemento más claro del trabajo de la $B D O$ en relación con las ediciones y la ilustración de las Metamorfosis. Por lo demás, en los últimos tiempos algunos investigadores de diversos países se han ocupado de aspectos de la ilustración de las ediciones y de algunas versiones en concreto, aportando nuevas perspectivas al conjunto que comienza a crecer y a mostrar la compleja realidad de la ilustración, en especial, del poema mitológico ovidiano. De especial relevancia a este respecto es el trabajo de M. Tung «The Interrelationship between Emblem Books and Ovid's Metamorphoses: A Survey of Research $\gg{ }^{17}$ porque abre unas perspectivas interesantes para la indagación de los temas y los motivos concretos ${ }^{18}$.

14 AMIELLE, G., Recherches sur des traductions françaises des Metamorphoses d'Ovide, illustrées et publiées en France à la fin du XVe siècle at au XVIe siècle, Paris, 1989, y BLATTNER, E., Holzschnittfolgen zu den Metamorphoses des Ovid, Venedig 1497 und Mainz 1545, München, 1998.

15 «L'iconografia della mitologia antica fra Quattro e Cinquecento. Edizioni illustrate delle $\mathrm{Me}$ tamorfosi di Ovidio», Studi Umanistici Piceni, 12, 1992, pp. 123-133; FREEDMAN, L. y HUBER-REBENICH, G. (eds). Ikonographische Repertorien zur Rezeption des antiken Mythos in Europa, Berlín, 1995 (3 vols.); Metamorphosen der 'Metamorphosen': Ovids Verwandlungssagen in der textbegleitenden Druckgraphik. Rudolstadt, 1999; «Kontinuität und Wandel in der frühen italienischen Ovid-Illustration. Die Tradition der Holzschnitte zu Giovanni dei Bonsignoris. Ovidio metamorphoseos vulgare», en MAREK, H., NEUSCHÄFER, A. y TICHY, S. (eds.), Metamorphosen: Wandlungen und Verwandlungen in Literatur, Sprache und Kunst von der Antike bis zur Gegenwar Festschrift für Bodo Guthmüller zum 65. Geburtstag, Wiesbaden, Harrassowitz Verlag, 2002, pp. 63-79.

16 HUBER-REBENICH, G., LÜTKEMEYER, S. y WALTER, H., Ikonographisches Repertorium zu den Metamorphosen des Ovid. Die textbegleitende Druckgraphik, I, Berlin, 2014; HUBER-REBENICH, G., LÜTKEMEYER, S. y WALTER, H., Ikonographisches Repertorium zu den Metamorphosen des Ovid. Sammeldarstellungen: Die textbegleitende Druckgraphik, Berlin, 2004.

17 Emblematica, 17, 2009, pp. 41-147.

18 Este artículo constituye el punto de partida de algunos trabajos en marcha sobre la relación de las ilustraciones de las Metamorfosis, con el mundo de la Emblemática y otros entornos figurados que se sirven del mismo tipo de lenguaje entre la metáfora y la metonimia relacionados con el conocimiento que procede de la $B D O$ (DÍEZ PLATAS, F., «Encuentros mitológicos: historias e imágenes ovidianas en las divisas personales», ponencia en las Jornadas de Investigación: Representación simbólica por la palabra y la imagen: divisas, emblemas y otras agudezas de la cultura visual (siglos XIV-XVII), Santiago, 24-25 de mayo de 2018). Una interesante aproximación se encuentra ya en el trabajo de B. Guthmüller sobre la Picta poesis (vide supra n. 12). 
Por otra parte, la tendencia en los estudios sobre el Ovidio ilustrado en aquellos momentos ya se empezaba a orientar hacia el campo de la difusión. Progresivamente, el interés en torno a Ovidio y las imágenes creadas para las Metamorfosis comenzó a centrarse más bien en las cuestiones relacionadas con la recepción de la tradición clásica que toman forma en diversos sitios web de universidades y bibliotecas que desarrollaron proyectos de difusión en formato digital de las ediciones ilustradas que se alojan en sus fondos ${ }^{19}$. También se han abordado estudios de recepción con especial interés en la influencia de la obra de Ovidio en las artes plásticas, entre los que destaca, sin duda, el proyecto dedicado a las Metamorfosis dentro del sitio ICONOS de la Universidad de La Sapienza, (Roma), que aspira a ser una gran base de datos iconográfica sobre los episodios mitológicos que se analizan desglosados, con sus antecedentes griegos y su pervivencia, y que toma como base de la clasificación la exposición de los temas y objetos que se encuentra en las Metamorfosis ${ }^{20}$.

Con estos antecedentes, la $B D O$ inició su andadura en el campo de la difusión patrimonial, pero con la mirada puesta en el conocimiento y en el enfoque iconográfico en relación con la imagen generada por la ilustración de las obras de Ovidio. El objetivo final es la realización del estudio conjunto y completo de las ediciones ilustradas de las Metamorfosis y del resto de las obras, abordando a fondo las cuestiones de representación y narración dentro de la estructura figurativa, pero, como ya hemos indicado, somos conscientes de que esta es una tarea que requiere tiempo, porque implica el conocimiento completo de las tradiciones de ilustración de las obras ovidianas.

\section{PROCESOS, TAREAS Y METODOLOGÍA DE LA $B D O$}

En este apartado quisiéramos exponer de manera esquemática y concisa cuáles son los procesos, las tareas y actividades del proyecto, haciendo hincapié en algunas cuestiones metodológicas que constituyen la novedad primordial de la $B D O$.

19 Metamorphosing the 'Metamorphoses': The Ovid Project, Universidad de Vermont, EE.UU.: http://www.uvm.edu/ hag/ovid [Consulta: 20/11/2020] y, de una manera especial, Ovid illustrated: The Renaissance Reception of Ovid in image and text, un completo, aunque algo caótico, sitio de Internet dentro de la biblioteca digital de la Universidad de Virginia (EE.UU.), que contiene la digitalización de una enorme cantidad de ediciones ilustradas del poema ovidiano con comentarios, bibliografía y enlaces con otros proyectos: https://ovid.lib.virginia.edu/ovidillust.html [Consulta: 20/11/2020].

20 http://www.iconos.it/index.php?id=1 [Consulta: 20/11/2020]. 


\subsection{Objetivos y tareas}

En primer lugar, expondremos las tareas concretas que constituyen los objetivos específicos del desarrollo del proyecto:

i. La primera de ellas es la localización e identificación de los ejemplares ilustrados de las obras de Ovidio en las bibliotecas con fondo antiguo. Una primera búsqueda se realiza a través de los catálogos en red, partiendo del Catálogo Colectivo de Patrimonio Bibliográfico Español $(C C P B)$, que recupera el número de bibliotecas con fondo antiguo en las que se podrían encontrar ediciones de Ovidio, además de los ejemplares que se encuentran en las citadas bibliotecas. Esta no supone, sin embargo, una búsqueda definitiva, puesto que el $C C P B$ es todavía un proyecto en fase de construcción y no un catálogo terminado. Búsquedas en webs de archivos y bibliotecas completan la localización de los posibles fondos con obras de Ovidio. El siguiente paso en esta tarea consiste en establecer el contacto con las bibliotecas. En los casos en los que sabemos que existen ediciones de Ovidio entre sus fondos, solicitamos permiso para su consulta; en las que no, demandamos primero si desde la propia biblioteca pueden confirmarnos si poseen o no obras que sean de interés para nuestro proyecto.

ii. La segunda de las tareas es la visita a la biblioteca para realizar la consulta y la elaboración de las fichas biblio-iconográficas de cada uno de los ejemplares identificados. Esta consulta de los especímenes in situ constituye uno de los trabajos más importantes que realizamos, pues es el que nos va a proporcionar toda la información primaria sobre los ejemplares de cada biblioteca. En cada una de las bibliotecas que visitamos reseñamos las ediciones de Ovidio que se conservan y procedemos realizar una primera versión de la ficha de cada uno de ellos. Esta tarea de «autopsia», en sentido estricto, de cada uno de los ejemplares es ineludible, porque cada ejemplar es único, de modo que es necesario comprobar todas sus peculiaridades, especialmente en el aspecto de la ilustración, pues puede ocurrir que las estampas hayan sido censuradas, estén arrancadas o, incluso, se hayan movido de sitio por una reencuadernación posterior, que falten porque el libro esté mutilado, etc. Por otro lado, la consulta in situ en cada una de las bibliotecas permite encontrar muchos más ejemplares de los que en un principio teníamos constancia a través de las consultas de los catálogos en red. Aunque esto cada vez es menos habitual, todavía existen muchas bibliotecas que tienen parte o la totalidad de su fondo antiguo sin catalogar, y la 
búsqueda debe realizarse a través de los antiguos ficheros manuales, o incluso de otros modos menos organizados.

iii. La tercera tarea que realizamos con los ejemplares es el fotografiado o digitalización de la portada y los grabados de cada uno de los ejemplares identificados como ilustrados. Cuando la institución nos lo permite, realizamos nosotros mismos el fotografiado; cuando esto no es posible, pedimos las digitalizaciones.

iv. La cuarta tarea consiste en la elaboración final de las fichas biblio-iconográficas y el estudio de los ejemplares y ediciones ilustrados. Una vez realizado el trabajo de campo, se revisa y se refina la información de la ficha biblio-iconográfica realizada en la biblioteca, lo que de manera práctica se convierte en un estudio específico de cada uno de los ejemplares y de la edición a la que representan.

v. A continuación, la quinta tarea consiste en procesar la información completa de las fichas terminadas e incorporarla a la base de datos que conforma la $B D O$. Esta información incluye también las imágenes de portadas y grabados, debidamente tratados en cuanto a forma y a identificación.

vi. En sexto lugar, reseñamos una tarea que se simultanea con el resto y que está activa constantemente. Se trata de la actualización y el perfeccionamiento de la plataforma digital en relación con la presentación y acceso de los contenidos y con la intención de convertir a la $B D O$ plenamente en un recurso digital abierto.

vii. Por último, es una tarea del proyecto la elaboración de estudios de conjunto sobre la presencia de las ediciones ilustradas en las bibliotecas de las comunidades estudiadas. Esta labor, como se puede ver en el apartado de resultados, se está desarrollando con lentitud porque el estudio de los ejemplares se produce de forma desigual, de modo que, hasta que no conocemos y podemos documentar de manera correcta todas las ediciones a las que pertenecen los ejemplares de un fondo, no abordamos el estudio de conjunto para que no resulte una mirada superficial o, sencillamente, parcial. De este modo, el estudio de la ilustración de Ovidio no se puede completar de manera autónoma en cada una de las fases del proyecto, puesto que es una tarea de conjunto que implica toda la información que se va consiguiendo en cada una de las fases del proyecto global que constituye la $B D O$. 


\subsection{Novedades metodológicas}

Por lo que se refiere a cuestiones específicas del método de trabajo, una de las principales novedades metodológicas que aporta el trabajo del proyecto $B D O$ ha sido el modelado de la información que se vierte en la base de datos. Con este objetivo se ha diseñado con cuidado la ficha-estudio que se elabora de cada uno de los ejemplares. Como ya hemos indicado se trata de una ficha que denominamos biblio-iconográfica creada ex profeso para reflejar la información necesaria y pertinente sobre cada uno de los especímenes estudiados y digitalizados. De manera concreta, la ficha de trabajo de la $B D O$ (Fig. 1) refleja más información y contenido que las fichas bibliográficas al uso. Además de los datos básicos, como título, autor, obra, lugar de impresión o fecha, contiene información crucial para nuestro trabajo, como el impresor, el comitente y el ilustrador. Campos como «contenido», en donde se desglosan las partes incluidas en el libro con su correspondiente paginación o foliación, o «historial» en el que se recogen los exlibris y la información que pueda conocerse sobre antiguos poseedores del ejemplar, posibles donaciones, en definitiva, sobre la vida de cada ejemplar.

Aunque la verdadera novedad de la ficha biblio-iconográfica de la $B D O$ se encuentra en los campos relacionados con la ilustración, Por un lado, el apartado de «características de la edición», donde se desglosa la información sobre el texto que incluye, los autores de los comentarios, en caso de tenerlos, información sobre el tipo de ilustración, las fuentes, los modelos, posibles paralelos, ediciones en las que se hayan utilizado los mismos grabados, o copias similares, es decir, un pequeño estudio sobre la edición y su aparato figurativo. Por otro lado, la «lista de ilustraciones», donde se refleja la configuración de cada ejemplar como obra ilustrada, con la relación completa de los grabados, su situación en la edición y los episodios que representan, lo que supone una primera lectura iconográfica (Fig. 2). Se detallan además elementos característicos de cada ejemplar en cada uno de los grabados en el caso de que hayan sido censurados o pintados, si falta alguno, o si se encuentra situado en un lugar diferente al que corresponde a la edición, incluida la información sobre inscripciones propias de la imagen o añadidos manuscritos. Finalmente, la base de datos diseñada contiene, como veremos, un reflejo de esta ficha bibliográfico-iconográfica propia.

Por otra parte, el modelado de los datos -que se han jerarquizado de manera precisa para su introducción en la ficha- ha propiciado la creación de un sistema de identificación de ediciones y ejemplares, único y pertinente, que se traduce en la creación de dos tipos de código, uno para la edición y otro para el ejemplar concreto localizado en una determinada biblioteca. Ambos códigos facilitan la organización de la base de datos y de los materiales en el proceso de estudio. 
Así, para cada una de las ediciones de la obra ilustrada de Ovidio se ha creado un código de nominación que permite reconocer de manera inmediata la edición de la que se trata. El código se compone de la obra, seguida del nombre del editor, traductor o comentarista de la abreviatura (si se trata de una edición comentada o traducida), a continuación, el nombre del impresor, el lugar de impresión y la fecha: Metamorfosis/M.Bustamante.Bellero.Amberes.1595, corresponde a la traducción de las Metamorfosis realizada por Jorge de Bustamante y editada con una serie de grabados por Pedro Bellero en Amberes en 1595. El código del ejemplar, por su parte, es una descripción abreviada de la edición, el ejemplar y la biblioteca que lo posee, de modo que se reseña en abreviatura la obra, el acrónimo de la biblioteca, el lugar de publicación y el año: M.BXU.Amb.1595 se corresponde con el ejemplar de la mencionada traducción que se encuentra en la Biblioteca Xeral de la Universidad de Santiago de Compostela, cuyo acrónimo es $\mathrm{BXU}^{21}$. De esta manera aparecen listadas las ediciones y los ejemplares en el sitio web (Fig. 3), lo que facilita una rápida identificación de las obras, las ediciones y los ejemplares dentro de las bibliotecas que los poseen ${ }^{22}$.

\subsection{Desarrollo, mejora y mantenimiento de la plataforma digital}

Unos de los objetivos fundamentales del proyecto desde sus inicios ha sido la difusión conjunta del corpus compilado a través de la construcción de una biblioteca digital de la obra ilustrada de Ovidio, alojada en un dominio propio, que es lo que da sentido al proyecto en su realidad actual ${ }^{23}$. Por esta razón, ha sido especialmente relevante el proceso de desarrollo, mejora y mantenimiento de la plataforma digital, que ha tenido también varias etapas.

En un primer momento, procedimos a crear: a) una base de datos relacional con un modelo conceptual basado en el esquema de «copo de nieve», que permite una ordenación de la información más adecuada; b) un sitio web que cumple una serie de requisitos, centrados sobre todo en la funcionabilidad y la usabilidad; c) cinco vías de acceso a la información que permiten al investigador realizar búsquedas diversas de acuerdo con sus campos de interés: cronológico

21 En la exigua descripción del ejemplar se pueden producir raros casos de coincidencia entre los ejemplares de ediciones distintas que, sin embargo, se publican en el mismo lugar en la misma fecha y que a estas alturas de desarrollo del estudio están prácticamente todos contemplados. Para ello se han establecido sencillos métodos de desambiguación que consisten en la adición de dígitos o letras que marcan las diferencias

22 Lista de ediciones de la $B D O$ : http://www.ovidiuspictus.es/listadoediciones.php [Consulta: 20/11/2020].

23 http://www.ovidiuspictus.es/bdo.php [Consulta: 20/11/2020]. 
(por siglos); patrimonial (por bibliotecas); una lista de todas las ediciones; un motor de búsqueda que incluye formatos novedosos como impresor, ilustrador o episodio mitológico, y una línea temporal; d) una versión en inglés para facilitar el acceso a un mayor número de usuarios.

El sitio Web Biblioteca Digital Ovidiana presenta, por tanto, varias novedades. La principal radica en los diferentes modos de acceder a la información, en el que se potencian fundamentalmente dos tipos iniciales de ordenación de los datos: el cronológico, mostrando la incidencia de las ediciones y los ejemplares por siglos, y el patrimonial, en relación con los fondos ovidianos de cada biblioteca. Estos constituyen las dos formas básicas y directas de consultas que permiten localizar ejemplares por siglos y por bibliotecas. Las búsquedas pueden realizarse, gracias a un motor de búsqueda, por formatos clásicos como título, obra, lugar de publicación o fecha, pero también incluyen otros campos más novedosos como impresor, ilustrador, y sobre todo el campo del tema de la ilustración, que permite averiguar en cuántas y cuáles ediciones aparece un motivo iconográfico, y recuperar todos los grabados asociados en los que aparece dicha imagen, personaje o episodio. A esto se unió en 2017 una nueva herramienta de consulta de temas y personajes mitológicos en forma de «nube de etiquetas $»^{24}$ con los términos en latín (Fig. 4) para facilitar el acceso y la consulta de la $B D O$ a los usuarios no hispanohablantes.

La otra novedad es la representación de los datos, de una forma visual e intuitiva. Los datos se presentan de una forma estructurada y ordenada en forma de ficha (Fig. 5), con pestañas que regulan la cantidad de información que se desea visualizar, por lo que el usuario puede gestionar siempre la información a la que accede. Las ilustraciones de cada ejemplar se pueden mostrar individualmente (Fig. 6) o en conjunto (Fig. 7), ofreciendo en ambos casos información de lo que se está visualizando y permitiendo contemplar con un solo golpe de vista todo el conjunto iconográfico de la edición a la que pertenecen.

Durante el año 2017 se desarrolló una nueva interfaz, más moderna y dinámica, que incorporó, además, nuevos recursos. De manera efectiva, en consonancia con el desarrollo y la ampliación de los objetivos de estudio, se creó un nuevo sitio: Ovidius Pictus ${ }^{25}$ que alberga la Biblioteca Digital Ovidiana (www.ovidiuspictus.es/BDO.php) y que aspira a convertirse en un portal y un repositorio sobre la investigación en la obra ilustrada de Ovidio (Fig. 8).

En los últimos tres años, el trabajo con la plataforma digital está orientado a la modificación del modelo digital. Para ello, se ha construido la primera

24 http://ovidiuspictus.es/etiquetas.php [Consulta: 20/11/2020].

25 www.ovidiuspictus.es/ www.ovidiuspictus.eu/www.ovidiuspictus.net. 
versión de la ontología de la Biblioteca Digital Ovidiana $(B D O)^{26}$. La ontología permitirá poner la información en abierto como datos abiertos enlazados y alinearlos con otras fuentes de información haciendo que el modelo de datos de la $B D O$ sea interoperable. Con la ontología, además, se lanzan nuevas propuestas que suponen un valor añadido como es la creación de un vocabulario controlado o tesauro que permita la clasificación de las obras y los ejemplares por la temática de las imágenes. Así mismo, se ha generado el grafo de conocimiento que se almacenará en un almacén de triples y además se cuenta con el conjunto de datos (dataset) con la información de los datos disponibles en la $B D O$ y se ha usado RDF como un modelo de datos flexible para representar la información extraída y para publicarla en la Web. Todos estos avances, no solo aportan ventajas de cara al usuario, sino que incrementarán las posibilidades de extraer e inferir información enriquecida, lo que permitirá dar respuesta a preguntas para la investigación y el análisis de los datos. Entre otros fines se pretende:

a) establecer patrones de posesión y lectura, según siglos y tipos de ediciones, diferencias entre las ediciones escolares, las traducciones, las ediciones comentadas y anotadas;

b) contemplar en su conjunto las ediciones y ejemplares y establecer relaciones desde las repeticiones, la evolución del modo de ilustración, detectar patrones de uso de los grabados, establecer tradiciones de uso de los grabados y detectar las relaciones entre editores y grabadores en relación con la obra ilustrada de Ovidio;

c) estudiar la repetición de los motivos y figuras más ilustrados, atendiendo a las preferencias y a la evolución de la ilustración del mito y la creación de tradiciones iconográficas ${ }^{27}$.

\section{UNA INVESTIGACIÓN MULTIDIMENSIONAL: RESULTADOS Y LOGROS DE LA BDO}

El primer resultado de un proyecto como la $B D O$ es ya en sí mismo el resultado de las tareas de trabajo y estudio, esto es, de la consulta, localización, estudio y digitalización de los ejemplares que se han ido incorporando a la biblioteca digital en las distintas fases. Sin embargo, como se ha visto en el desarrollo del

26 Disponible en https://github.com/OVIDIUSPICTUS/Biblioteca-Digital-Ovidiana [Consulta: 20/11/2020].

27 Una exposición detallada de este proceso se encuentra en DÍEZ PLATAS, M. L., DÍEZ PLATAS F. y CENTENERA CENTENERA, P., «Conectando el conocimiento: los datos abiertos de las ediciones ilustradas de Ovidio», que está en curso de publicación. 
proyecto a lo largo de estos trece años, las tareas realizadas en los fondos de las distintas bibliotecas, por una parte, han desembocado en el conocimiento de los fondos de las más variadas instituciones. Por otra, la investigación y el estudio de las ediciones ilustradas, unido al trabajo directo con los ejemplares concretos y con las ilustraciones, han producido una serie de resultados que se pueden agrupar en cuatro ámbitos diferentes de acuerdo con el objeto de estudio e investigación. En todo caso, la naturaleza de los resultados no se reduce a las publicaciones de trabajos de investigación, sino que abarca el campo de la difusión y la transferencia de conocimiento que resultan evidentes en proyectos de este tipo que incluyen una herramienta o una plataforma digital.

El primer ámbito en el que se han producido resultados es el de la propia Biblioteca Digital Ovidiana como repositorio de bibliotecas y de libros ilustrados. A ello se une el hecho de que se ha convertido en un instrumento de investigación en Humanidades Digitales y una herramienta en relación con el libro y las bibliotecas. En este sentido, la $B D O$ como repositorio, recurso y plataforma digital se ha presentado en numerosos foros, congresos, jornadas $\mathrm{y}$ reuniones científicas relacionadas, tanto con las Humanidades Digitales, como con las bibliotecas, la realidad y el sentido de las bibliotecas digitales y el mundo del libro y del libro ilustrado.

Desde que en 2012 el sitio web de la $B D O$ empieza a estar totalmente operativo y a albergar la digitalización y el estudio de los ejemplares, comenzó una labor de presentación y difusión en diversos ámbitos de divulgación como las Semanas de la Ciencia o en actividades de actualización científica sobre proyectos de investigación. Por otra parte, como repositorio de la obra de Ovidio, se hizo lógica la presentación y difusión del proyecto en foros y eventos de estudios clásicos, entre los que cobró especial relevancia la presentación del proyecto y del nuevo sistema de búsqueda desarrollado en 2017 -la nube de etiquetas en latín que se aloja en el sitio web (vide supra) - en un evento global en la Universidad Normal de Shanghai (China) ${ }^{28}$. La Biblioteca Digital Ovidiana ha encontrado asimismo un espacio natural en los ámbitos de estudio del libro -y en

28 Globalizing Ovid: An International Conference in Commemoration of the Bimillennium of Ovid's Death, Guangqi International Center for Scholars of Shanghai Normal University, Shanghai, 31 de mayo a 2 de junio, 2017. 
especial del libro ilustrado ${ }^{29}$ y de las bibliotecas ${ }^{30}$. En este campo del valor de la $B D O$ como recurso para la investigación del libro ilustrado y recurso para el trabajo en la biblioteca se han producido dos publicaciones de gran calado ${ }^{31}$.

Pero, sin duda, la $B D O$ se ha ido convirtiendo sobre todo en una realidad digital. En primer lugar, en relación con el proceso de digitalización como medio de conservación del patrimonio bibliográfico, pero también como una biblioteca digital temática en relación con el libro y la imagen ${ }^{32}$ y un proyecto en el que se ha puesto de relieve su naturaleza multidisciplinar en relación con el conocimiento $^{33}$. Por tanto, el proyecto $B D O$ se imbricó pronto en las realidades de las nacientes Humanidades Digitales, de modo que ha tenido una presencia constante en actividades y eventos relacionados con el arte y la historia del arte digital $^{34}$, y las posibilidades de las herramientas de digitalización ${ }^{35}$. Por esta razón, desde su origen los congresos de Humanidades Digitales Hispánicas han

29 En el reciente Congreso Internacional de Arte y Literatura «Diálogos en torno al libro: texto e imagen», (Albacete, 28-30 de octubre de 2020) parte del equipo del proyecto (Fátima Díez Platas, Patricia Meilán Jácome, Nerea Senra Alonso y Brianda Otero Moreira) hizo una presentación de la $B D O$ como herramienta para la investigación de las relaciones entre el texto y la imagen en el libro a través del poster «Un proyecto de libros e imágenes: la Biblioteca Digital Ovidiana: ediciones ilustradas de las obras de Ovidio en las bibliotecas españolas (siglos XV-XIX)».

30 El proyecto se presentó como biblioteca digital en las I Jornadas Gestión del Patrimonio Bibliográfico (CRUE-REBIUN) (Universidad de Castilla-Mancha, Toledo, 1-2 de junio de 2017) con la comunicación «Patrimonio selecto: reflexiones sobre el papel de la Biblioteca Digital Ovidiana y la difusión y conservación del patrimonio bibliográfico», elaborada por Fátima Díez Platas, Paloma Centenera Centenera y María Luisa Díez Platas, que se ha materializado en una publicación digital (RUIDERAe: Revista de Unidades de Información, $\mathrm{n}^{\circ}$ 12, 2017 [En línea: https://revista.uclm.es/index.php/ruiderae/article/view/1632. Consulta: 21/11/20].

31 DÍEZ PLATAS, F., «Researching illustrated books in art history: a brief history of the Biblioteca Digital Ovidiana project», en HOFFMAN, S. (ed.), Dynamic Research Support for Academic Libraries, London, Facet Publishing, 2016, pp. 21-32, y DÍEZ PLATAS, F, «Desde la imagen: la Biblioteca Digital Ovidiana como instrumento de estudio e investigación iconográfica del libro ilustrado», Studia Aurea. Revista de Literatura Española y Teoría Literaria del Renacimiento y Siglo de Oro, 11, 2017, pp. 55-72.

32 «A Virtual Museum-Library: The Case of the Ovidian Digital Library (Biblioteca Digital Ovidiana)», ponencia presentada por la investigadora principal en la Global Conference «Digital Memories and Digital Art History», Mansfield College, Oxford, 24-26 de septiembre de 2014.

33 «El proyecto de investigación Biblioteca Digital Ovidiana: una oportunidad para la interdisciplinariedad y la comunicación del conocimiento», ponencia presentada por Fátima Díez Platas y María Luisa Díez Platas, en la I Jornada Académica «Cultura de la unidad: Innovación y tradición en la universidad europea», A-SOPHIA, Madrid, 1-2 de noviembre de 2014.

34 Desde este punto de vista la $B D O$ ha encontrado un espacio de teorización en el seno de los encuentros científicos de arte e historia del arte digital que se han celebrado en Málaga en los años 2013, 2014 y 2016 bajo los auspicios de la ReArte.Dix (Red Internacional de Estudios Digitales sobre la Cultura Artística), a la que pertenece el proyecto.

35 «La Biblioteca Digital Ovidiana: una plataforma digital para el libro ilustrado», presentación de la investigadora principal en las Jornadas sobre Proyectos de Humanidades Digitales en la BNE, 14 de marzo de 2017. 
constituido uno de los espacios privilegiados en los que se han desarrollado la presentación $^{36} \mathrm{y}$ los avances del proyecto ${ }^{37} \mathrm{y}$ de la plataforma ${ }^{38}$.

El segundo ámbito de estudio e investigación en el que se han producido resultados es el que presenta a la $B D O$ como el repositorio específico de la obra ilustrada de Ovidio en las bibliotecas, es decir, el que explora de manera concreta las bibliotecas españolas como lugares de las imágenes ovidianas. En este aspecto se reseña el resultado de un trabajo de campo preciso que se realiza físicamente en la biblioteca para rastrear la presencia del «Ovidio ilustrado» en

36 En el I Congreso Internacional de la HDH: Humanidades Digitales: desafios, logros y perspectivas de futuro, organizado por la Universidade da Coruña (A Coruña, 9-12 de julio de 2013) se presentó un panel completo sobre el proyecto bajo el título «La Biblioteca Digital Ovidiana: un espacio virtual de recopilación y difusión patrimonial», en el que se incluyeron tres presentaciones en relación con aspectos del proyecto que en ese momento estaba en sus inicios: una sobre el objeto de investigación («Las ediciones ilustradas de Ovidio de los siglos XV al XIX», presentada por la investigadora principal; una presentación de la relación de la BDO con el estudio del patrimonio bibliográfico español presentado por Patricia Meilán Jácome («La Biblioteca Digital Ovidiana y el patrimonio bibliográfico español») y la presentación técnica en relación con el desarrollo de la biblioteca digital y su apertura («El proceso de desarrollo de una biblioteca digital y su apertura e integración en el recolector Hispana: El caso de la Biblioteca Digital Ovidiana Abierta), presentado por los miembros técnicos del proyecto Paloma Centenera Centenera y María Luisa Díez Platas. Las contribuciones se materializaron en sendas publicaciones dentro de la edición preparada por Sagrario López Poza y Nieves Pena Sueiro como editoras de Humanidades Digitales: desafios, logros y perspectivas de futuro. Janus, Anexo 1 (2014): MEILÁN JÁCOME, P. y DÍEZ PLATAS, F., «La Biblioteca Digital Ovidiana y el patrimonio bibliográfico español», pp. 317327, [Disponible en línea: https://www.janusdigital.es/anexos/contribucion.htm?id=29 Consulta: 20/11/20], y CENTENERA CENTENERA, P.; DÍEZ PLATAS, Mª L., «El proceso de desarrollo de una biblioteca digital y su apertura e integración en el recolector Hispana: El caso de la Biblioteca Digital Ovidiana Abierta», pp. 137-150 [Disponible en línea: https://www.janusdigital.es/anexos/contribucion.htm?id=13. Consulta: 20/11/20].

37 En el II Congreso Internacional de Humanidades Digitales Hispánicas (UNED, Madrid, 5-7 de octubre de 2015), la principal participación del proyecto consistió en la elaboración del panel «Proyecciones mitológicas: un uso digital, diversificado y didáctico de la Biblioteca Digital Ovidiana», que versó sobre las posibilidades académicas y de generación de contenidos de la Biblioteca Digital Ovidiana, presentado por la investigadora principal y el equipo de estudiantes que desarrollaron las aplicaciones prácticas.

38 En el II Congreso Internacional de Humanidades Digitales Hispánicas (UNED, Madrid, 5-7 de octubre de 2015), los miembros técnicos del equipo de investigación del proyecto Paloma Centenera y María Luisa Díez presentaron una comunicación sobre una herramienta desarrollada por ellas sobre el modelo de la BDO: «SAMEBibl: una solución para la migración de datos a Europeana». En el III Congreso de la Sociedad Internacional de Humanidades Digitales Hispánicas: Sociedades, políticas, saberes (Málaga, 18-20 de octubre de 2017), continuando con la exploración de la aplicación de las posibilidades de la $B D O$ como herramienta para investigación en Historia del Arte y en el aspecto de la ilustración y la iconografía, la investigadora principal y los miembros técnicos del equipo de investigación presentaron una comunicación sobre un aspecto que sigue en desarrollo en este momento: «La vida de las imágenes. Identificación de patrones en la ilustración de las Metamorfosis de Ovidio».

Por último, en el IV Congreso Internacional HDH2019. Humanidades Digitales \& Patrimonio Cultural, (Toledo, 23-25 de octubre de 2019), la investigadora principal y los dos miembros técnicos del proyecto presentaron una comunicación sobre el proceso de la apertura de la biblioteca: «Conectando el conocimiento: los datos abiertos de las ediciones ilustradas de Ovidio», que está en curso de publicación. 
las diferentes instituciones; un trabajo que todavía no está concluido y sigue en marcha con cada fase del proyecto. Estas tareas en ocasiones se vuelven momentos especialmente gratificantes con el hallazgo de piezas excepcionales que, con frecuencia, eran perfectas desconocidas para el mundo de la investigación ${ }^{39}$. El resultado de estos rastreos se ha presentado en diferentes foros y se han realizado ya algunas publicaciones sobre fondos excepcionales ${ }^{40}$, aunque todavía hay mucho trabajo en marcha.

En este aspecto, la última novedad entre los resultados del trabajo del proyecto ha sido la elaboración de un Blog sobre bibliotecas, sobre libros y sobre Ovidio (Fig. 9), que está alojado en el portal Ovidius Pictus ${ }^{41}$. En cada una de las entradas se presenta la historia y la realidad de una biblioteca concreta de las que se han visitado y estudiado y se muestran comentados los ejemplares ilustrados que posee. Por medio de este recurso se repasa desde un punto de vista diferente el conjunto de las obras ilustradas estudiadas que ya están incluidas en la Biblioteca Digital Ovidiana o que están todavía en fase de estudio. Los ejemplares se presentan en este caso como libros que pertenecen a un fondo histórico concreto dentro del conjunto de las distintas bibliotecas españolas que cuentan con ejemplares de las obras de Ovidio ilustradas. El recorrido del blog ha comenzado, como comenzó la andadura de la $B D O$, por las bibliotecas de la comunidad autónoma gallega y aspira a recorrer todas la bibliotecas visitadas y estudiadas a lo largo de las distintas fases del proyecto.

Fue precisamente el trabajo concluido con las bibliotecas gallegas lo que propició la realización de la que consideramos una de las actividades más relevantes como resultado del proyecto, la exposición: «Ovidius vivit! Mitos imágenes y libros. La obra ilustrada de Ovidio en las bibliotecas de Galicia», que se celebró en Santiago de Compostela entre mayo y julio de 2017. La muestra, comisariada por la investigadora principal y con la colaboración de todo el equipo de trabajo del proyecto, reunió más de setenta ejemplares ilustrados de las obras de Ovidio procedentes de catorce bibliotecas de Galicia. Los libros, que se dispusieron en tres ámbitos, fueron el instrumento para mostrar la

39 DÍEZ PLATAS, F., «Una presencia excepcional de Ovidio en Mondoñedo: la edición de Parma 1505», Estudios Mindonienses, 28, 2012, pp. 543-560.

40 DÍEZ PLATAS, F., MEILÁN JÁCOME, P., SENRA ALONSO, N. y GARCÍA GÓMEZ, E., «Un patrimonio excepcional: las ediciones ilustradas de Ovidio en el convento de San Francisco do Val de Deus (Santiago de Compostela)», Liceo Franciscano. Revista de Estudio e Investigación, año LXVIII, $n^{\circ}$ 208, 2017, pp. 297-323; DÍEZ PLATAS, F., «Patrimonio universitario: las ediciones ilustradas de las obras de Ovidio en la Biblioteca Xeral de la Universidad de Santiago de Compostela», Quintana, 17, 2018, pp. 167-190; DÍEZ PLATAS, F., «Académicos e ilustrados: los 'Ovidios' del Seminario Metropolitano de San Atón». Pax et Emerita, 16, 285-310.

41 http://bdovidiana.es [Consulta: 20/11/2020]. 
realidad de la personalidad del poeta y su obra («Ovidio, un poeta inmortal»), la historia de la ilustración de su obra más relevante, las Metamorfosis («Libros para mirar: la ilustración de las Metamorfosis del siglo XV al siglo XIX) y las imágenes del mito a través de los grabados presentes en las distintas ediciones («Imágenes para leer: la iconografía de las Metamorfosis). La exposición constituyó un importante hito en el conocimiento de la ilustración de la obra de Ovidio al presentar la principal novedad: la línea temporal completa del desarrollo de la ilustración de las Metamorfosis desde el siglo XV al siglo XIX (Fig. 10), en la que se individualizaba cada una de las ediciones que supusieron una novedad en relación con la ilustración y con la relación del texto con la imagen, que se consideran ediciones «príncipes iconográficas», de acuerdo con un nuevo concepto acuñado por F. Díez Platas ${ }^{42}$.

De este modo, el conocimiento de la ilustración de las obras de Ovidio y de su tradición se ha constituido en el tercero de los ámbitos de estudio, investigación y teorización de los miembros del equipo del proyecto $B D O$, que ya está produciendo algunos resultados interesantes ${ }^{43}$. A este respecto es necesario decir que el trabajo con la tradición de la ilustración de las obras ovidianas, y de manera especial de las Metamorfosis, ha conducido los intereses de investigación hacia el mundo medieval en búsqueda de los antecedentes de la figuración de las historias mitológicas relacionadas con el texto de Ovidio. Esto ha abierto un campo específico de investigación al que se han acogido varios miembros del equipo del proyecto que están realizando su tesis doctoral sobre aspectos del Ovidio medieval que se presenta como un novedoso, y solo en parte explorado, campo de investigación.

Por último, el conocimiento de la ilustración de las obras de Ovidio, y de manera especial de las Metamorfosis, como ya hemos indicado, y el trabajo concreto y detallado con los ejemplares que se encuentran en las bibliotecas españolas ha propiciado el desarrollo de una línea de investigación puramente

42 DÍEZ PLATAS, F., «Desde la imagen: la Biblioteca Digital Ovidiana como instrumento de estudio e investigación iconográfica del libro ilustrado», en Studia Aurea. Revista de Literatura Española y Teoría Literaria del Renacimiento y Siglo de Oro 11, 2017, p. 70.

43 Véase a este respecto: DÍEZ PLATAS, F., «Et per omnia saecula imagine vivam: The completion of a figurative corpus for Ovid's Metamorphoses in the XVth and XVIth century book illustrations», en MACK, P. y NORTH, J. (eds.), The afterlife of Ovid (BICS Supplement 130), London, 2015, pp. 115135, y «Glosas visuales: la imagen y las ediciones latinas de las Metamorfosis de Ovidio a inicios del siglo XVI», en La fisonomía del libro medieval y moderno: entre la funcionalidad la estética y la información, In culpa est, 8, Zaragoza, Prensas de la Universidad de Zaragoza, 2019, pp. 211-222; MEILÁN JÁCOME, P., «Transformaciones de una edición de Ovidio: sobre las Metamorfosis de Ovidio de Francisco Crivell (1805-1819) », en PEDRAZA GRACIA, M. J. (dir.), In culpa est. Doce siglos de materialidad del libro. Estudios sobre manuscritos e impresos entre los siglos VIII y XIX, Zaragoza, Prensas de la Universidad de Zaragoza, 2017, pp. 543-559. 
iconográfica sobre los temas y motivos que se originan a partir de la obra de Ovidio desde el inicio, en la pintura pompeyana, pero, de manera concreta, como ilustraciones desde la iluminación de los manuscritos de las distintas obras del poeta -en las que la primacía, insistimos, la tiene el poema de las Metamorfosis - hasta el presente. El conocimiento de las tradiciones de ilustración y los aparatos figurativos de las ediciones facilita un conocimiento experto en relación con la figuración de los temas y las figuras mitológicas que permite, además, indagar sobre los mecanismos de la imagen como medio ${ }^{44}$. En este aspecto también se está trabajando en el seno del proyecto, lo que se ha materializado en ponencias y comunicaciones y en algunas publicaciones en relación con una serie de figuras concretas como el dios Baco, Orfeo o el Minotauro, entre otras, realizadas por los distintos miembros del proyecto.

\section{BIBLIOGRAFÍA}

AMIELLE, G., Recherches sur des traductions françaises des Metamorphoses d'Ovide, illustrées et publiées en France à la fin du XVe siècle at au XVIe siècle, Paris, 1989.

BLATTNER, E., Holzschnittfolgen zu den Metamorphoses des Ovid, Venedig 1497 und Mainz 1545, München, 1998.

CENTENERA CENTENERA, P. y DÍEZ PLATAS, $M^{\mathrm{a}}$ L., «El proceso de desarrollo de una biblioteca digital y su apertura e integración en el recolector Hispana: El caso de la Biblioteca Digital Ovidiana Abierta», en LÓPEZ POZA, S. y PENA SUEIRO, N. (eds.), Humanidades Digitales: desafios, logros y perspectivas de futuro. Janus, Anexo 1, 2014, pp. 137-150 [Disponible en línea: https://www.janusdigital.es/anexos/contribucion.htm?id=13]. DÍEZ PLATAS, F., Imágenes para un texto. Guía Iconográfica de las 'Metamorfosis' de Ovidio Santiago de Compostela, Tórculo, 2000.

DÍEZ PLATAS, F., «Tres maneras de ilustrar a Ovidio: una aproximación al estudio iconográfico de las Metamorfosis figuradas del XVI», en FOLGAR, M C., GOY, A. y LÓPEZ, J. M. (eds.), Memoria Artis I, Santiago de Compostela, Xunta de Galicia, 2003, pp. 247-267.

44 De manera concreta sobre lo que supone ilustrar poesía, acompañándola o transformándola en figuración. Sobre estos aspectos: DÍEZ PLATAS, F. y MEILÁN JÁCOME, P., «Le poète dans son œuvre. Ovide dans les images des Fastes et des Tristia aux XVe et XVIe siècles», Anabases 29, 2019, pp. $253-$ 265, y DÍEZ PLATAS, F, 奥维德的图像 : 神话和诗歌的形式与掩饰 (“Images for Ovid: shapes and disguises for myth and poetry»), en J. Liu, 全球视野下的古罗马诗人奥维德研究前沿 (The New Frontiers of Research on the Roman Poet Ovid in the Global Context), Peking University Press, Peking, 2020, pp. 298-313, que está en el proceso final de publicación. 
DÍEZ PLATAS, F., «El Minotauro: ¿una imagen 'al pie de la letra'?», Quintana, 4, 2005, pp. 141-152.

DÍEZ PLATAS, F., «El viaje de Orfeo, de la Antigüedad a la tradición clásica», Jornadas Insulae. La multiculturalidad en la Antigüedad clásica, Tenerife, 2007.

DÍEZ PLATAS, F., «Una presencia excepcional de Ovidio en Mondoñedo: la edición de Parma 1505», Estudios Mindonienses, 28, 2012, pp. 543-560.

DÍEZ PLATAS, F., «Et per omnia saecula imagine vivam: The completion of a figurative corpus for Ovid's Metamorphoses in the XVth and XVIth century book illustrations», en MACK, P. y NORTH, J. (eds.), The afterlife of Ovid (BICS Supplement 130), London, 2015, pp. 115-135.

DÍEZ PLATAS, F., «Researching illustrated books in art history: a brief history of the Biblioteca Digital Ovidiana project», en HOFFMAN, S. (ed.), Dynamic Research Support for Academic Libraries, London, Facet Publishing, 2016, pp. 21-32.

DÍEZ PLATAS, F, «Desde la imagen: la Biblioteca Digital Ovidiana como instrumento de estudio e investigación iconográfica del libro ilustrado», Studia Aurea. Revista de Literatura Española y Teoría Literaria del Renacimiento y Siglo de Oro, 11, 2017, pp. 55-72.

DÍEZ PLATAS, F., «Patrimonio universitario: las ediciones ilustradas de las obras de Ovidio en la Biblioteca Xeral de la Universidad de Santiago de Compostela», Quintana, 17, 2018, pp. 167-190.

DÍEZ PLATAS, F., «Glosas visuales: la imagen y las ediciones latinas de las Metamorfosis de Ovidio a inicios del siglo XVI», en La fisonomía del libro medieval y moderno: entre la funcionalidad la estética y la información, In culpa est, 8, Zaragoza, Prensas de la Universidad de Zaragoza, 2019, pp. 211-222.

DÍEZ PLATAS, F., «Académicos e ilustrados: los 'Ovidios' del Seminario Metropolitano de San Atón», Pax et Emerita, 16, pp. 285-310.

DÍEZ PLATAS, F, 奥维德的图像 : 神话和诗歌的形式与掩饰 («Images for Ovid: shapes and disguises for myth and poetry»), en J. Liu, 全球视野下的 古罗马诗人奥维德研究前沿 (The New Frontiers of Research on the Roman Poet Ovid in the Global Context), Peking, Peking University Press, 2020, pp. 298-313.

DÍEZ PLATAS, F., CENTENERA CENTENERA, P. y DÍEZ PLATAS, $\mathrm{M}^{\mathrm{a}} \mathrm{L}$., «Patrimonio selecto: reflexiones sobre el papel de la Biblioteca Digital Ovidiana y la difusión y conservación del patrimonio bibliográfico», RUIDERAe: Revista de Unidades de Información, $\mathrm{n}^{\circ}$ 12, 2017 [En línea: https://revista.uclm.es/index.php/ruiderae/article/view/1632]. 
DÍEZ PLATAS, F., GARCÍA GÓMEZ, E., PAZ FERNÁNDEZ, M. y LÓPEZ GÓMEZ, C., «Mitos de libro: la ilustración de las Metamorfosis de Ovidio en las ediciones españolas del siglo XVI», en GARCÍA MAHÍQUES, R. y ZURIAGA SENENT, V. F. (eds.), Imagen y Cultura. La Interpretación de las Imágenes como Historia Cultural I, Valencia, Biblioteca Valenciana, 2008, pp. 549-562.

DÍEZ PLATAS, F. y MEILÁN JÁCOME, P., «Le poète dans son œuvre. Ovide dans les images des Fastes et des Tristia aux XVe et XVIe siècles», Anabases, 29, 2019, pp. 253-265.

DÍEZ PLATAS, F., MEILÁN JÁCOME, P., SENRA ALONSO, N. y GARCÍA GÓMEZ, E., «Un patrimonio excepcional: las ediciones ilustradas de Ovidio en el convento de San Francisco do Val de Deus (Santiago de Compostela)», Liceo Franciscano. Revista de estudio e investigación, año LXVIII, ${ }^{\circ} 208$, 2017, pp. 297-323.

DÍEZ PLATAS, F. y MONTERROSO MONTERO, J. M., «Mitología para poderosos: las Metamorfosis de Ovidio. Tres ediciones ilustradas del siglo XVI en la Biblioteca Xeral de Santiago», en VIGO, A. (ed.), Cultura, poder y mecenazgo, Semata 10, Santiago de Compostela, 1998, pp. 451-472.

FREEDMAN, L. y HUBER-REBENICH, G. (eds.), Ikonographische Repertorien zur Rezeption des antiken Mythos in Europa, Berlín, 1995 (3 vols.).

GUTHMÜLLER, B., "Immagine e testo nelle Trasformationi di Ludovico Dolce», en Mito, poesia, arte. Saggi sulla tradizione ovidiana nel Rinascimento, Roma, Bulzoni Editore, 1997, pp. 291-307.

GUTHMÜLLER, B., «Picta poesis Ovidiana», en HEITMANN, K. y SCHROEDER, E. (eds.), Renatae Litterae: Studien zum Nachleben der Antike und zur europäischen Renaissance: August Buck zum 60. Geburtstag, Frankfurt. 1973 (versión italiana en Mito, poesía, arte: saggi sulla tradizione ovidiana nel Rinascimento, Roma, 1997, pp. 213-236.

HENKEL, M. D., De Houtsneden van Mansion's Ovide moralisé, Bruges 1484, Amsterdam, 1922.

HENKEL, M. D., «Illustrierte Ausgaben von Ovids Metamorphosen im XV., XVI. und XVII. Jahrhundert», en Vorträge der Bibliothek Warburg (19261927), 1930, pp. 53-144.

HUBER-REBENICH, G., Metamorphosen der 'Metamorphosen': Ovids Verwandlungssagen in der textbegleitenden Druckgraphik. Rudolstadt, 1999.

HUBER-REBENICH, G., LÜTKEMEYER, S. y WALTER, H., Ikonographisches Repertorium zu den Metamorphosen des Ovid. Die textbegleitende Druckgraphik, I, Berlin, 2014. 
HUBER-REBENICH, G., LÜTKEMEYER, S. y WALTER, H., Ikonographisches Repertorium zu den Metamorphosen des Ovid. Sammeldarstellungen: Die textbegleitende Druckgraphik, Berlin, 2004.

HUBER-REBENICH, G., «Kontinuität und Wandel in der frühen italienischen Ovid-Illustration. Die Tradition der Holzschnitte zu Giovanni dei Bonsignoris. Ovidio metamorphoseos vulgare», en MAREK, H., NEUSCHÄFER, A. y TICHY, S. (eds.), Metamorphosen: Wandlungen und Verwandlungen in Literatur, Sprache und Kunst von der Antike bis zur Gegenwar Festschrift für Bodo Guthmüller zum 65. Geburtstag, Harrassowitz Verlag, Wiesbaden, 2002, pp. 63-79.

HUBER-REBENICH, G., «L'iconografia della mitologia antica fra Quattro e Cinquecento. Edizioni illustrate delle Metamorfosi di Ovidio», Studi Umanistici Piceni 12, 1992, pp. 123-133.

MEILÁN JÁCOME, P. y DÍEZ PLATAS, F., «La Biblioteca Digital Ovidiana y el patrimonio bibliográfico español», en LÓPEZ POZA, S. y PENA SUEIRO, N. (eds.), Humanidades Digitales: desafios, logros y perspectivas de futuro. Janus, Anexo 1, 2014.pp. 317-327 [Disponible en línea: https://www.janusdigital.es/anexos/contribucion.htm?id=29].

MEILÁN JÁCOME, P., «Transformaciones de una edición de Ovidio: sobre las Metamorfosis de Ovidio de Francisco Crivell (1805-1819)», en PEDRAZA GRACIA, M. J. (dir.), In culpa est. Doce siglos de materialidad del libro. Estudios sobre manuscritos e impresos entre los siglos VIII y XIX, Zaragoza, Prensas de la Universidad de Zaragoza, 2017, pp. 543-559.

TUNG, M., «The Interrelationship between Emblem Books and Ovid's Metamorphoses: A Survey of Research», Emblematica, 17, 2009, pp. 41-147. 

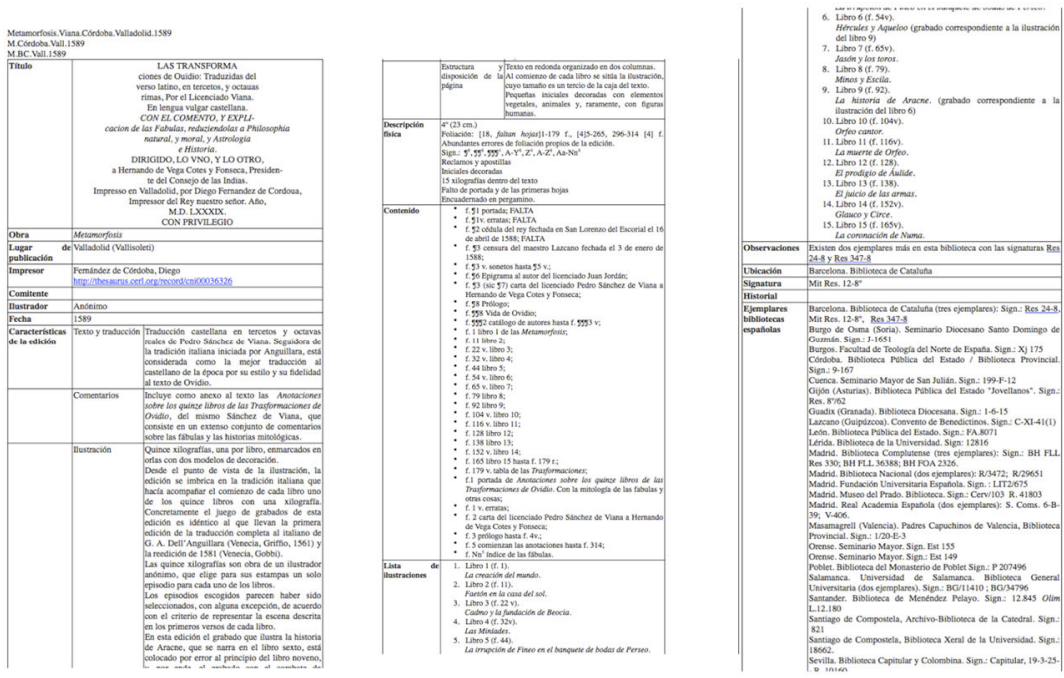

1. Ficha biblio-iconográfica del ejemplar de la traducción al español de las $M e$ tamorfosis de Sánchez de Viana publicada en Valladolid en 1589 (M.BC. Vall.1589=ejemplar de la Biblioteca de Cataluña)

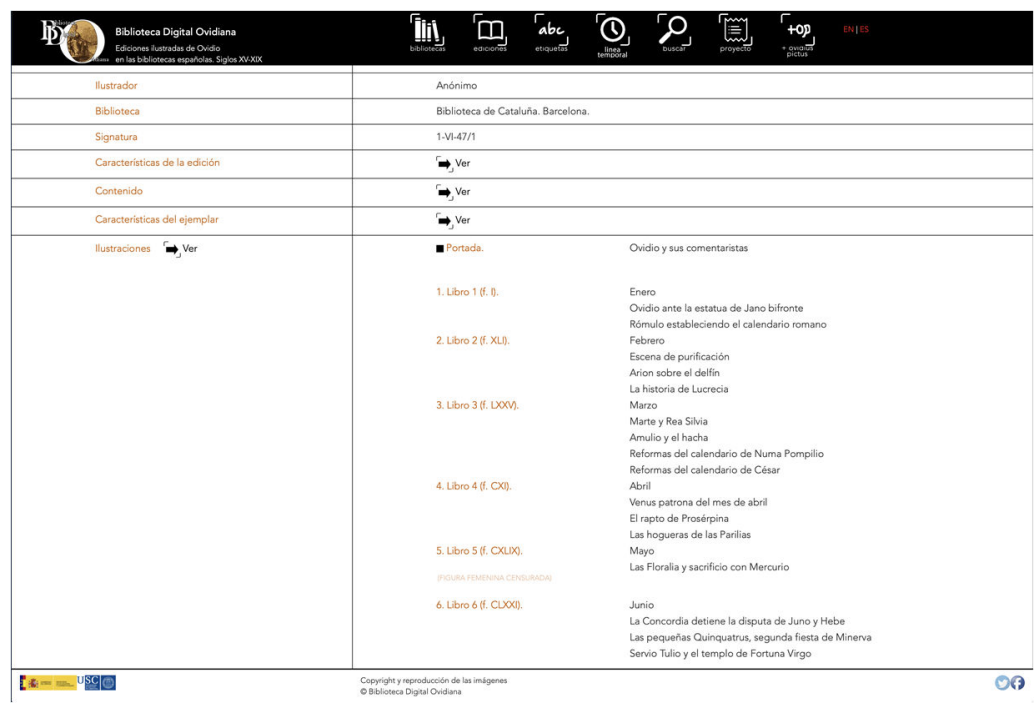

2. Detalle de la lista de ilustraciones del ejemplar de los Fastos editados en Venecia en 1508 ( F.BC.Ven.1508=ejemplar de la Biblioteca de Cataluña) 


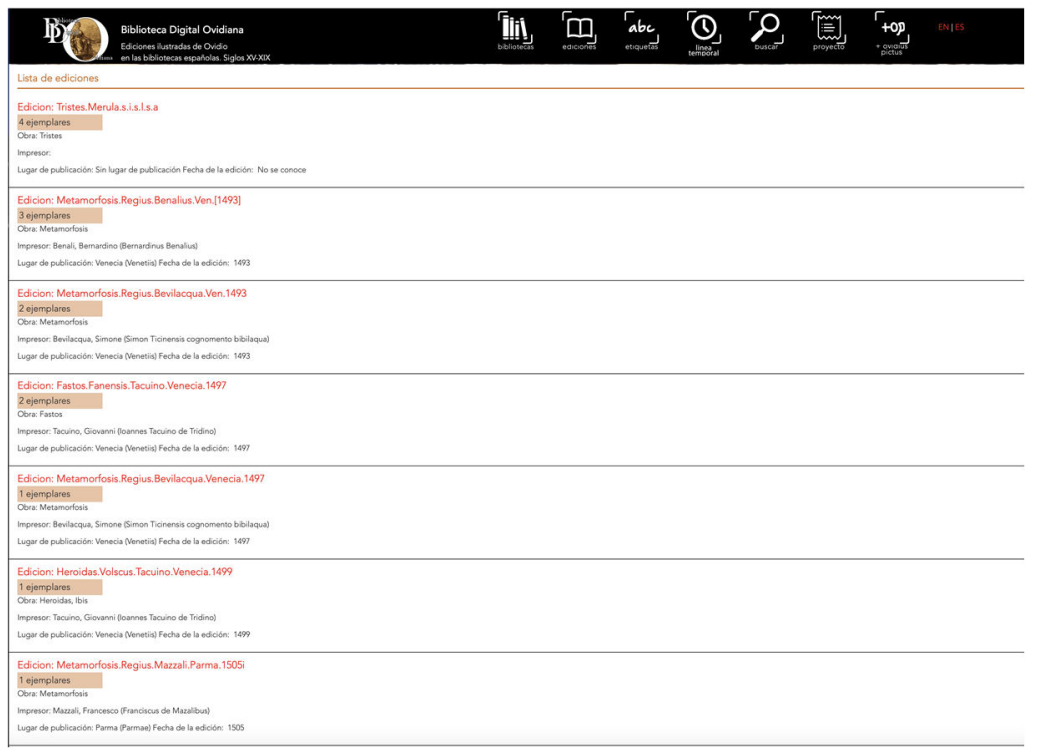

3. Detalle de la lista de ediciones del sitio Web. Biblioteca Digital Ovidiana
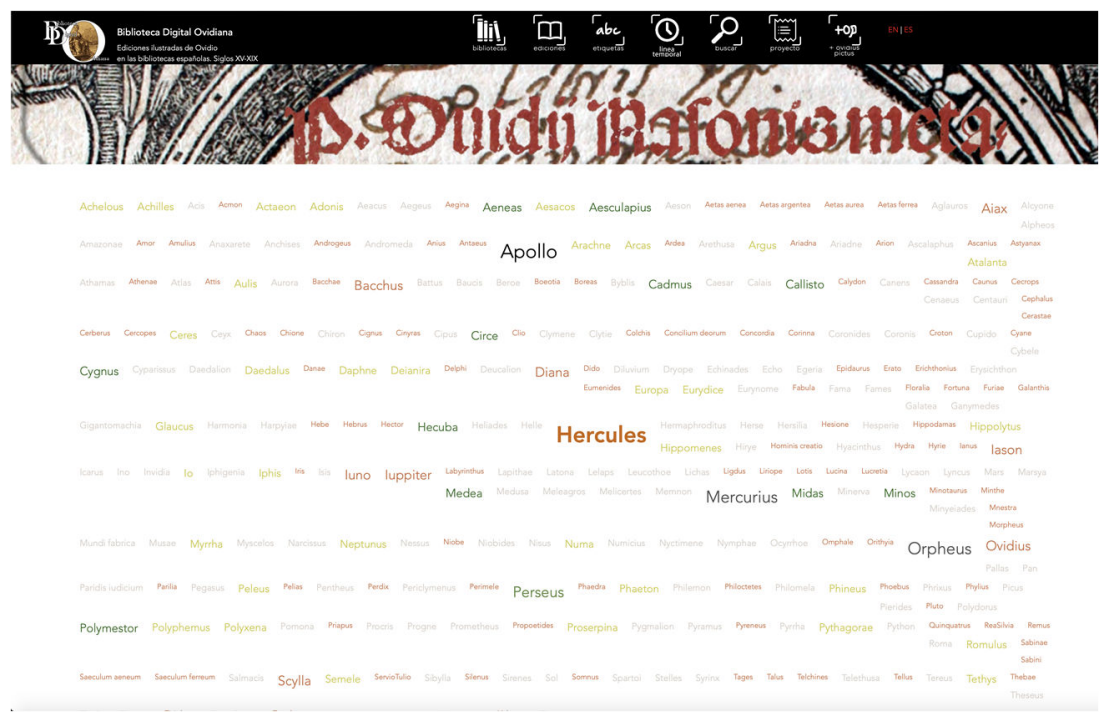

4. Nube de etiquetas. Biblioteca Digital Ovidiana 


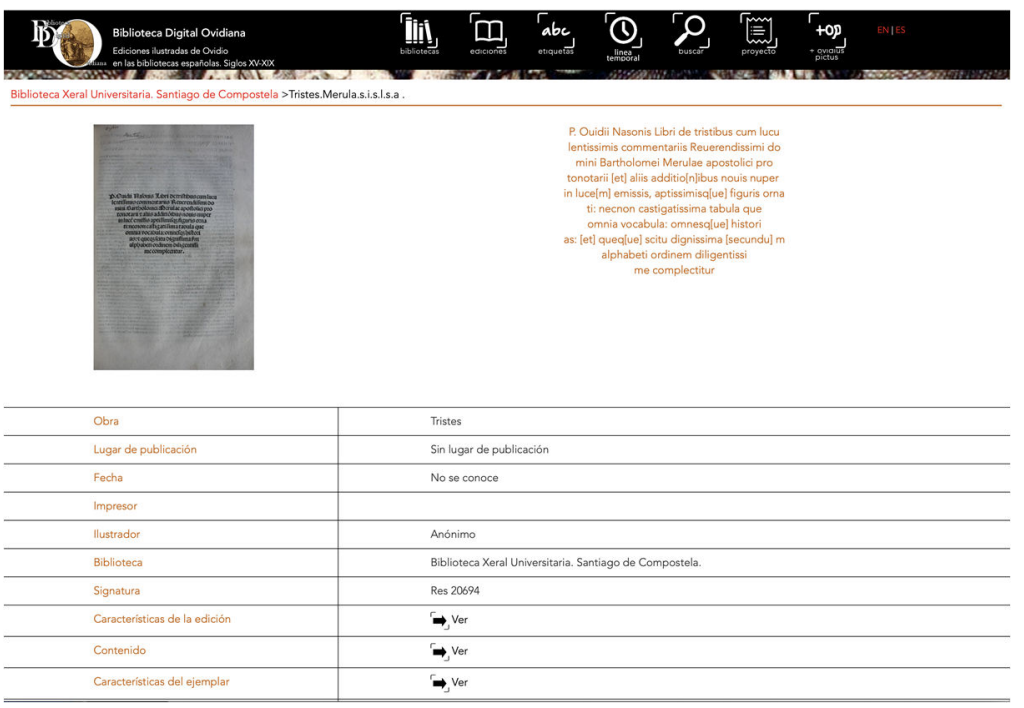

5. Visualización en el sitio Web de la ficha del ejemplar de las Tristes sin lugar ni fecha de publicación ( T.BXU.s.l.s.a =ejemplar de la Biblioteca Xeral Universitaria de Santiago)

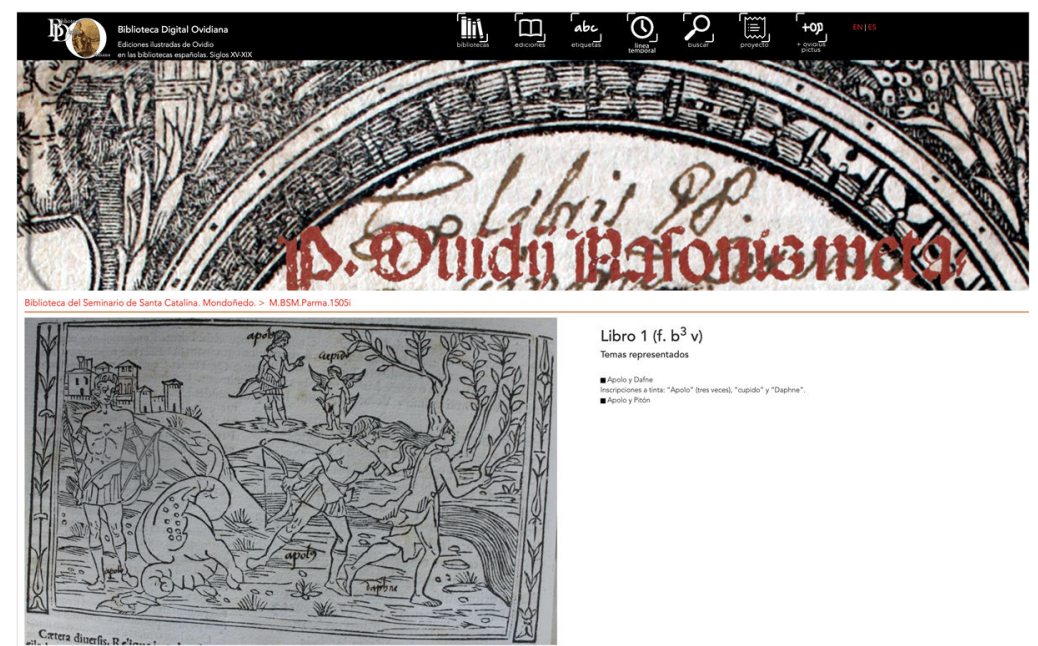

6. Detalle del grabado del libro 1que representa el episodio de Apolo y Pitón y la historia de Apolo y Dafne Edición latina de las Metamorfosis publicada en Parma en 1505. (M.BSM.Parma.1505i=ejemplar del Seminario de Santa Catalina de Mondoñedo, Lugo) 


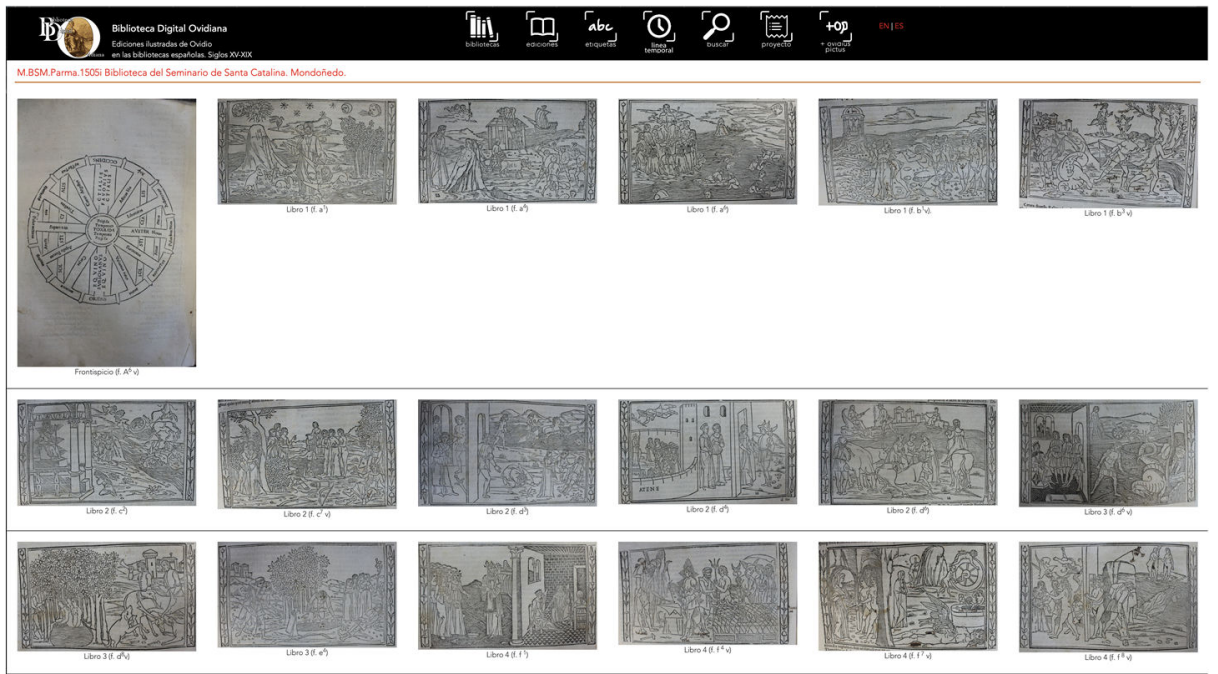

7. Detalle de la galería de imágenes del ejemplar. (M.BSM.Parma.1505i=ejemplar del Seminario de Santa Catalina de Mondoñedo, Lugo)

\section{Q. onouspecus}
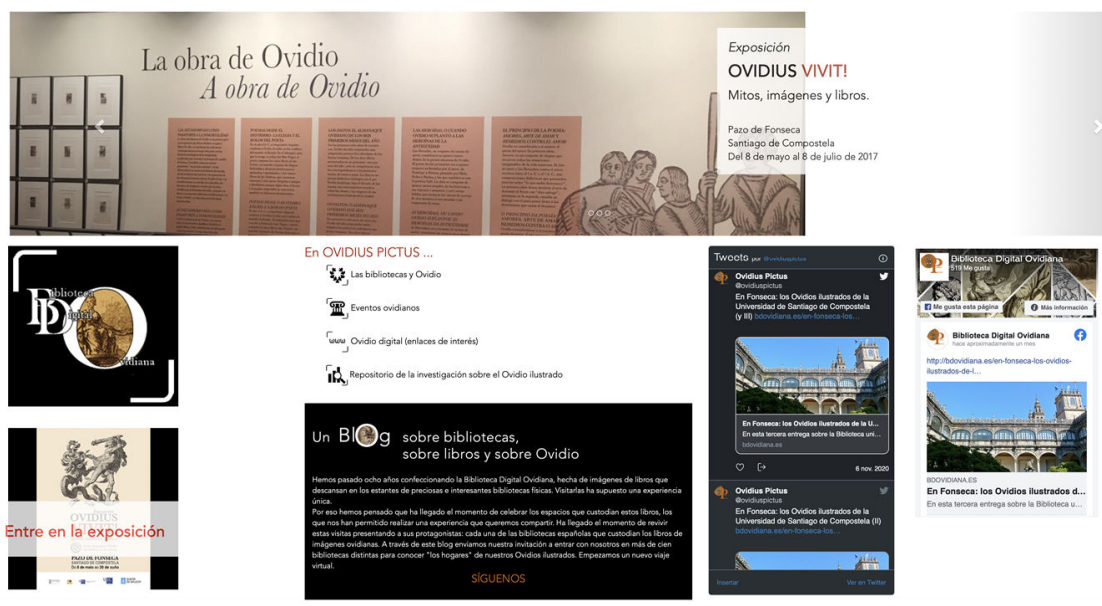

8. Visualización de la página de inicio del portal Ovidius Pictus 


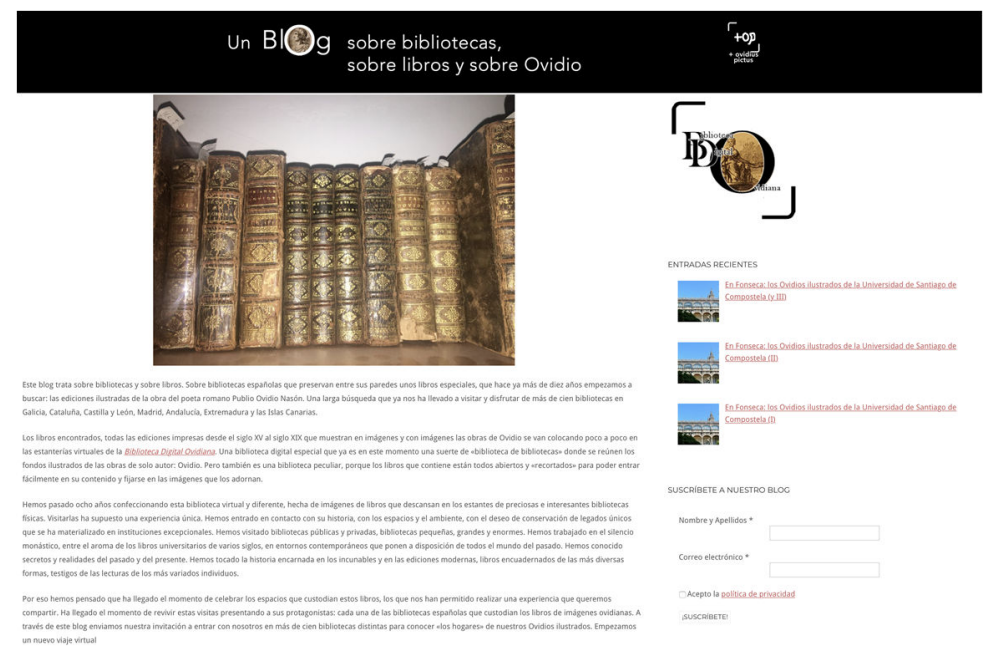

Visualización de la página de inicio del blog Sobre bibliotecas, sobre libros y sobre Ovidio.

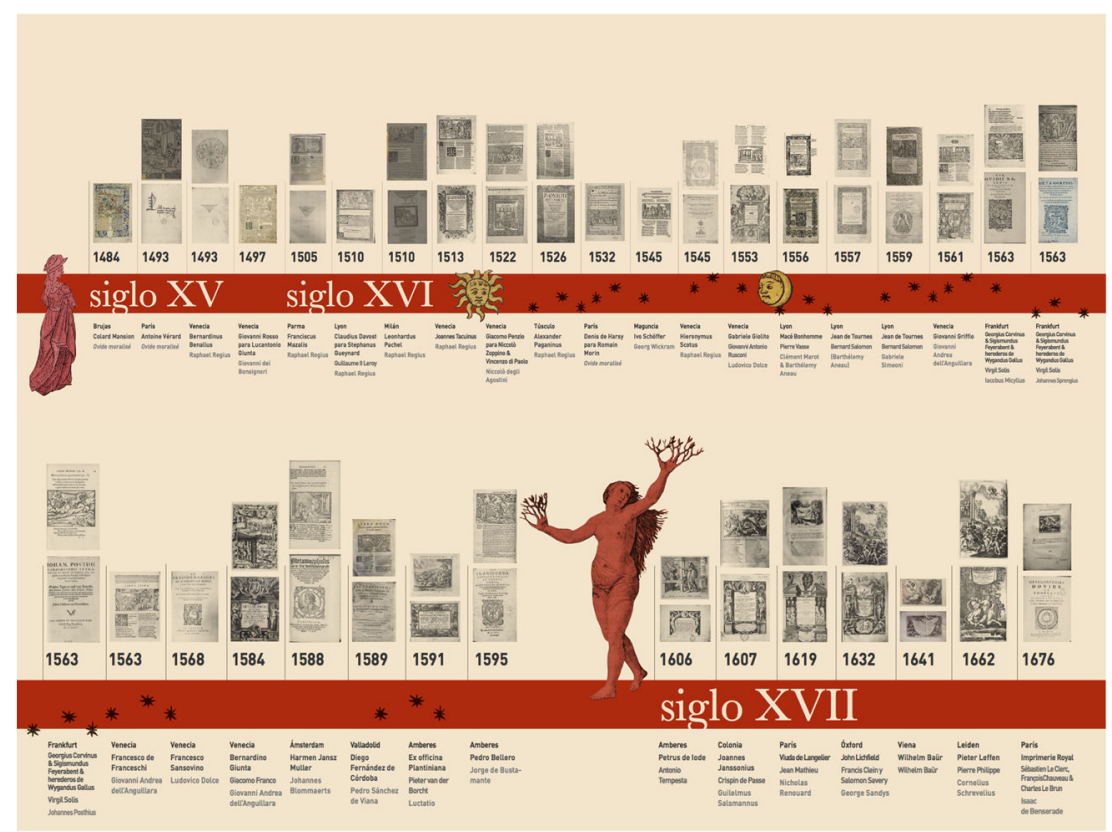

9. Detalle de la línea temporal de las ediciones ilustradas de las Metamorfosis. Exposición Ovidius vivit! 
Fátima Díez Platas

Departamento de Historia del Arte Universidad de Santiago de Compostela Plaza de la Universidad, 1

15782 Santiago https://orcid.org/0000-0002-4474-2431

fatima.diez@usc.es 